\title{
Silent primary ovarian ectopic pregnancy following ovulation induction: diagnostic dilemma
}

\author{
Kalyani Saidhandapani ${ }^{1}$, Yashaswi Pandey ${ }^{1 *}$, Priya Shaunthini' ${ }^{2}$
}

\begin{abstract}
${ }^{1}$ Department of Obstetrics and Gynaecology, Southern Railway Headquarters Hospital, Chennai, Tamil Nadu, India ${ }^{2}$ Department of Radiology, Southern Railway Headquarters Hospital, Chennai, Tamil Nadu, India
\end{abstract}

Received: 18 July 2021

Accepted: 09 August 2021

\section{*Correspondence:}

Dr. Yashaswi Pandey,

E-mail: dryashaswijnp@gmail.com

Copyright: (c) the author(s), publisher and licensee Medip Academy. This is an open-access article distributed under the terms of the Creative Commons Attribution Non-Commercial License, which permits unrestricted non-commercial use, distribution, and reproduction in any medium, provided the original work is properly cited.

\begin{abstract}
Early diagnosis of an ovarian pregnancy, of all the diagnoses relating to extrauterine gestations, is perhaps a diagnostic challenge faced by an obstetrician and a radiologist. About $0.5 \%$ of extrauterine implantations occur in the ovary. Recent studies have demonstrated infertility and Assisted reproductive techniques (ARTs), multiparity, use of intrauterine devices as risk factors for ovarian ectopic. Knowledge pertaining to ovulation induction and risk of ovarian ectopic is even more scant. In this article, we report a case report of ovarian pregnancy following ovulation induction with letrozole. Patient visited with history of missed menstrual period, mild abdominal pain and a weakly positive urine pregnancy test. Provisional diagnosis of right tubal ectopic was made. Diagnosis of ruptured ovarian ectopic was made on explorative laparoscopy which was later confirmed histopathologically. Patient had normal intra and post-operative course. An ovarian ectopic can present as a life-threatening condition and a high index of suspicion can prevent morbidity as well as mortality. Ovarian pregnancy in a primigravida with ovulation induction without an alarming sign, as in this case, is the rarest entity came across till date.
\end{abstract}

Keywords: Ovarian ectopic, Assisted reproductive techniques, Ovulation induction, Letrozole

\section{INTRODUCTION}

Diagnosis of a silent ovarian ectopic pregnancy imposes challenge to the obstetrician as well as the radiologist. It is one of the rare entities in clinical practise with incidence of ovarian ectopic being $0.3-3 \%$.

Ovarian pregnancy is a very rare complication of both spontaneous and ART-induced pregnancies. ${ }^{2}$ It usually ends in rupture before the end of first trimester. There has been a significant challenge in differentiating between a tubal and ovarian ectopic pregnancy. An ovarian ectopic following ovulation induction with letrozole is an unusual phenomenon. A ruptured corpus luteal cyst often mimics ovarian ectopic and distinguishing them from each other may be difficult as the sonographic image of a wellvascularized ring within the ovary may be difficult to interpret.
We reported a case of primary ovarian ectopic pregnancy following ovulation induction with letrozole which was initially diagnosed as tubal ectopic and posted gor emergency explorative laparoscopy. Diagnosis of ruptured ovarian ectopic was made intra-operatively which was later confirmed histopathologically.

\section{CASE REPORT}

A 26 years old nulligravida, presented to our setup with primary sub-fertility for 3 years. Her past medical, surgical and family history was unremarkable with normal 30 days ovulatory cycles. A hysterosalpingogram (HSG) demonstrated a normal uterine cavity with bilateral tubes patent. Assessment of her ovarian reserves was predictive of polycystic ovaries with numerous antral follicles (AFC) and baseline follicular study depicting multiple small follicles with no dominant follicle. Patient's husband was 
a healthy 29 years old man with a normal semen analysis by WHO criteria. ${ }^{3}$

Patient underwent ovulation induction with letrozole 2.5 $\mathrm{mg}$ from day 3-7 of cycle followed by follicular study. On day 17, patient had a dominant follicle on right side measuring $1.8 \times 1.5 \mathrm{~cm}$ and endometrial thickness of 0.95 $\mathrm{cm}$. She was advised timed intercourse in the present cycle. She visited our OPD with history of missed menstrual period at 5 weeks of amenorrhea, mild abdominal pain and a weakly positive urine pregnancy test. Upon her visit to hospital, she had normal vital signs and mildly tender abdomen with right sided forniceal and cervical motion tenderness on digital vaginal examination. A transvaginal ultrasound demonstrated a significant amount pelvic collection with internal echoes. No intrauterine pregnancy was observed, and a suspicious mass was seen in the right adnexa measuring $5.2 \times 5.6 \mathrm{~cm}$ with echogenic ring lesion of $1.5 \times 1.1 \mathrm{~cm}$ size and ring of fire appearing vascularity. Trans-abdominal ultrasound was suggestive of significant fluid in Morrison's pouch. Provisional diagnosis of right tubal ectopic was made.

An urgent laparoscopy was performed shortly after provisional diagnosis. Intra-operatively, the uterus was normal in size, with moderate hemoperitonium and both fallopian tubes were normal. After aspiration of the blood, a ruptured right ovarian ectopic pregnancy was identified. The right ovary was enlarged with a bluish red mass of size $4 \times 4 \mathrm{~cm}$, with oozing of blood from the surface of the mass. Right-sided partial ovariectomy was attempted but couldn't be done. Proceeded with right salpingooopherectomy, the contents were evacuated and sent for histopathology that later confirmed the diagnosis. Patient was transfused 1-unit packed cells in view of acute blood loss and low haemoglobin levels in post-operative period. Rest post-operative period was uneventful. Patient was then discharged on post-op day 06 with the advise to avoid conception for 6 months.

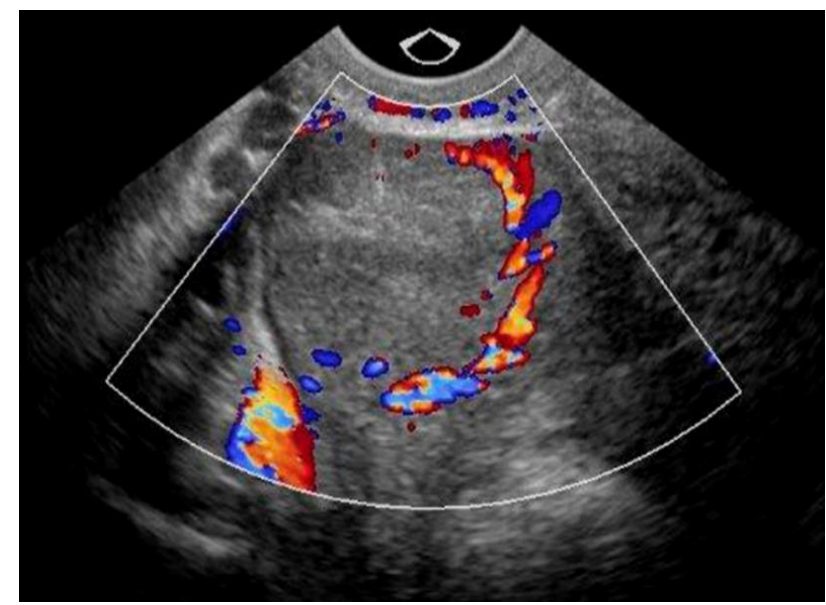

Figure 1: Image of transvaginal ultrasound showing hypoechoic lesion in right adnexa with echogenic ring lesion and ring of fire appearing vascularity on colour Doppler flow suggestive of ovarian ectopic.

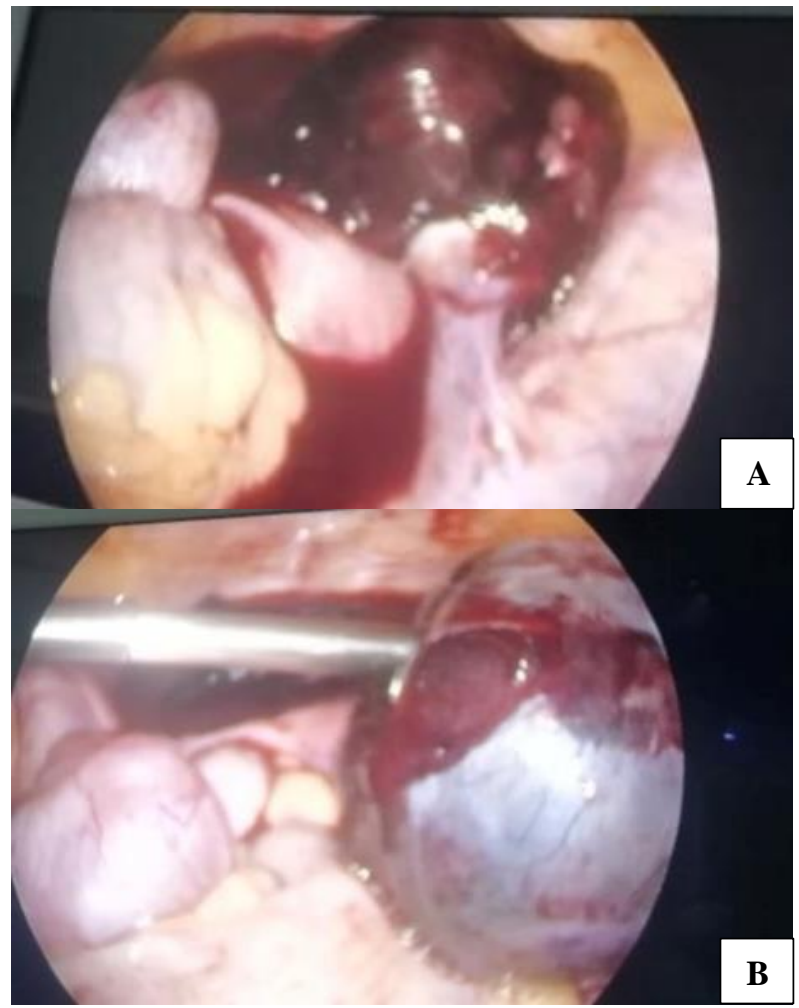

Figure 2: (A) Hemoperitoneum observed laproscopically; and (B) ruptured ovarian ectopic with blood clots covering the bluish ovarian surface.

\section{DISCUSSION}

Following fertilization and fallopian tube transit, the blastocyst normally implants in the endometrial lining of uterine cavity. Implantation elsewhere is considered ectopic and accounts for 0.5-1.5\% of all first trimester pregnancies. Ectopic implantation of the fertilized egg in the ovary is rare. ${ }^{4}$ With few exceptions, the initial diagnosis is made intra-operatively and the final diagnosis only on histopathology on the basis of the four criteria, outlined by Spiegelberg: (a) ipsilateral tube is intact and distinct from the ovary; (b) ectopic pregnancy occupies the ovary; (c) ectopic pregnancy is connected by the uteroovarian ligament; and (d) ovarian tissue demonstrated histologically amid the placental tissue. ${ }^{5}$

The etiology of an ovarian pregnancy is currently unknown but postulated causes include a failure of follicular extrusion and/or secondary implantation of a tubal pregnancy. ${ }^{6}$ Various risk factors for an ovarian ectopic have been described, including pelvic inflammatory disease, the use of intrauterine devices, endometriosis and assisted reproductive technologies. ${ }^{7}$ Although the ovary can accommodate the expanding pregnancy more easily than the fallopian tube, rupture at an early stage is the usual consequence. Transvaginal sonography use has resulted in a more frequent diagnosis of unruptured ovarian pregnancies. A wide ring that appears more echogenic than surrounding ovarian parenchyma is suggestive of an ovarian ectopic 
pregnancy. ${ }^{8}$ In contrast, a corpus luteum cyst is typically characterized by lower wall echogenicity than the endometrium or ovarian stroma. ${ }^{9}$ Classically, the management for ovarian pregnancies has been surgical. Small lesions can be managed by ovarian wedge resection or cystectomy, whereas larger lesions require oopherectomy. With conservative surgeries, beta-hCG levels should be monitored to exclude remanant trophoblatic tissue. Medical therapy with Methotrexate has been used in the treatment of ovarian ectopic pregnancy but trials are still inconclusive. According to the American Society of Reproductive Medicine guidelines, a beta-hCG level more than $5000 \mathrm{mIU}$ is a relative contraindication to medical therapy. ${ }^{10}$ There is no data available on the fixed dosing, frequency or route of administration of methotrexate in such patients.

As in our case, although the patient was hemodynamically stable with no symptoms other than mild abdominal pain, but sonographic picture was suggestive of no intra-uterine gestational sac with right adnexal hypoechoic lesion with ring of fire appearing vascularity and significant pelvic collection. A provisional diagnosis of tubal ectopic was suspected and then proceded for explorative laproscopy. In patients undergoing fertility treatment, a high index of suspicion is the mainstay even in the presence of an intrauterine pregnancy and in asymptomatic patients. Histolopathology remains the gold standard diagnosis of an ovarian pregnancy.

\section{CONCLUSION}

An ovarian ectopic following ovulation induction with letrozole has not been studied in detail and needs further focus in this area. Ovarian pregnancy presents with symptoms similar to tubal ectopic pregnancy. Several authors have described an increased risk of ovarian pregnancy among fertile patients undergoing ovulation induction treatment. ${ }^{11}$ Risk factors for an ovarian ectopic includes chronic pelvic inflammatory disease, insertion of intra-uterine devices, history of ARTs, ovarian stimulation, infertility and endometriosis. These risk factors must be kept in mind while evaluating a case of ectopic gestation. With the advent of Transvaginal ultrasonography, diagnosis of ovarian ectopic has increased. Still it imposes a challenge to the clinician and may prove as a life-threatening condition for the patient. Recurrence after an ovarian ectopic has till now not been noted unlike in tubal ectopic pregnancies where, it is found commonly. In cases of ovarian preservative surgeries, weekly beta-hCG follow up till negative must be done.
Funding: No funding sources

Conflict of interest: None declared

Ethical approval: Not required

\section{REFERENCES}

1. Valien JS, Reyero AMP, González MMA, García MM, Nieves DC. Ectopic ovarian pregnancy. An Med Interna. 1995;12(4):192-4.

2. Marcus SF, Brinsden PR. Analysis of the incidence and risk factors associated with ectopic pregnancy following in-vitro fertilization and embryo transfer. Hum Reprod. 1995;10(1):199-203.

3. Cooper TG, Noonan E, Eckardstein S, Auger J, Baker HW, Behre HM, et al. World Health Organization reference values for human semen characteristics. Hum Reprod Update. 2010;16(3):231-45.

4. Cunningham F, Leveno K, Bloom S, Spong CY, Dashe J. Williams obstetrics. 24th ed. New York, NY: McGraw Hill; 2014.

5. Panda S, Darlong LM, Singh S, Borah T. Case report of a primary ovarian pregnancy in a primigravida. $\mathrm{J}$ Hum Reprod Sci. 2009;2(2):90-2.

6. Bontis J, Grimbizis G, Tarlatzis BC, Miliaras D, Bili H. Intrafollicular ovarian pregnancy after ovulation induction/intrauterine insemination: pathophysiological aspects and diagnostic problems. Hum Reprod. 1997;12(2):376-8.

7. Einenkel J, Baier D, Horn LC, Alexander $\mathrm{H}$. Laparoscopic therapy of an intact primary ovarian pregnancy with ovarian hyperstimulation syndrome: case report. Hum Reprod. 2000;15(9):2037-40.

8. Honigl W, Reich O. Vaginosonographie bei ovarieller Gravidität. Ultraschall in der Medizin. 1997;18(5):233-6.

9. Stein MW, Ricci ZJ, Novak L, Roberts JH, Koenigsberg M. Sonographic comparison of the tubal ring of ectopic pregnancy with the corpus luteum. J Ultrasound Med. 2004;23(1):57-62.

10. Practice Committee of American Society for Reproductive Medicine. Medical treatment of ectopic pregnancy. Fertil Steril. 2008;90(5):206-12.

11. Fernandez H, Coste J, Spira N. Controlled ovarian hyperstimulation as a risk factor for ectopic pregnancy. Obstet Gynecol. 1991;78(4):656-9.

Cite this article as: Saidhandapani K, Pandey Y, Shaunthini P. Silent primary ovarian ectopic pregnancy following ovulation induction: diagnostic dilemma. Int J Reprod Contracept Obstet Gynecol 2021;10:3654-6. 